\section{A Minimum Difference Between 2 Syndromes}

García Núnez I ${ }^{1}$, Algaba Mármol MA²

${ }^{1}$ Allergy Department, Hospital Quironsalud Malaga, Malaga, Spain

${ }^{2}$ DCCU Ecija, Osune Primary Care Unit, Osuna, Spain

J Investig Allergol Clin Immunol 2017; Vol. 27(3): 201-202 doi: 10.18176/jiaci.0156

Key words: Kounis syndrome. Takotsubo syndrome. Levofloxacin. Heart failure.

Palabras clave: Síndrome de Kounis. Síndrome de Takotsubo. Levofloxacino. Fallo cardiaco.

To the Editor:

We are grateful to Kotsiou et al [1] for their excellent explanation of the similarities and differences between Kounis syndrome and Takotsubo syndrome. The information these authors provide in their letter will be of enormous help to the scientific community and will play a key role in educating health professionals about these syndromes.

With respect to the case we reported [2], I agree that the diagnosis could be Takotsubo syndrome, because it shares several clinical and diagnostic criteria with Kounis syndrome. Although full details are not provided in our case report, the patient underwent ergometry with echocardiography before and after the test while he was an inpatient, and the results were normal. Consequently, we ruled out the diagnosis of Takotsubo syndrome, because the diagnostic criteria defined by Abe and Kondo [3] and after that by researchers from the Mayo Clinic [4,5] are as follows:

1. Transient hypokinesis, akinesis, or dyskinesis in the left ventricular mid segments with or without apical involvement; regional wall motion abnormalities that extend beyond a single epicardial vascular distribution; and frequently, but not always, a stressful trigger

2. Absence of obstructive coronary disease or angiographic evidence of acute plaque rupture

3. New ECG abnormalities (ST-segment elevation and/ or T-wave inversion) or modest elevation in cardiac troponin

4. Absence of pheochromocytoma and myocarditis

Obviously, with the absence of this complementary study, the diagnosis could be Takotsubo syndrome or Kounis syndrome. However, the echocardiography-confirmed myocardial function rules out Takotsubo syndrome, because ergometry and/or electrocardiography can be temporally altered in this condition.

On the other hand, and depending on the etiology reported, Takotsubo syndrome can occur after a stressful trigger, including sepsis, although it is typically described in patients experiencing very intense emotional or physical stress [4,6-10].
No association with drug intake has been reported, unless this occurred in patients with sepsis.

To conclude, I also agree with the observations of Kounis et al [11] in their recent article on Kounis syndrome after intake of levofloxacin, because it is very important to improve our knowledge of Kounis syndrome and other similar syndromes associated with the release of mediators, as is the case in Takotsubo syndrome. A firm diagnosis is essential in order to improve treatment and prevent new cases (if this is at all possible) and deaths diagnosed as acute and severe myocardial infarction. A comprehensive clinical report and in vivo and in vitro complementary tests could facilitate clinical practice in these conditions.

\section{Funding}

The authors declare that no funding was received for the present study.

\section{Conflicts of Interest}

The authors declare that they have no conflicts of interest.

\section{References}

1. Kotsiou OS, Xirogiannis KI, Gourgoulianis KI. Kounis Syndrome: Is it Really a Takotsubo-Like Syndrome? J Investig Allergol Clin Immunol. 2017;27(3):198-200.

2. García Núñez I, Algaba Mármol MA, Barasona Villarejo MJ, Suárez Vergara M, Espínola González F, Reina Ariza E. Kounis Syndrome After Levofloxacin Intake: A Clinical Report and Cross-reactivity Study. J Investig Allergol Clin Immunol. 2016:26:335-6.

3. Abe $Y$, Kondo M. Apical ballooning of the left ventricle: a distinct entity? Heart. 2003;89:974-6.

4. Prasad A. Apical ballooning syndrome: an important differential diagnosis of acute myocardial infarction. Circulation. 2007;115: e56-9.

5. Prasad A, Lerman A, Rihal CS. Apical ballooning syndrome (TakoTsubo or stress cardiomyopathy): a mimic of acute myocardial infarction. Am Heart J. 2008;155:408-17.

6. Gianni M, Dentali F, Grandi AM, Sumner G, Hiralal R, Lonn E. Apical ballooning syndrome or takotsubo cardiomyopathy: a systematic review. Eur Heart J. 2006;27:1523-9.

7. Farzaneh-Far R, Farzaneh-Far A. Cardiovascular events during World Cup Soccer. N Engl J Med. 2008;358:2408-9; author reply 09 .

8. Bybee KA, Prasad A. Stress-related cardiomyopathy syndromes. Circulation. 2008;118:397-409.

9. Tsuchihashi K, Ueshima K, Uchida T, Oh-mura N, Kimura $K_{\text {, }}$ Owa M, Yoshiyama M, Miyazaki S, Haze K, Ogawa H, Honda T, Hase M, Kai R, Morii l; Angina Pectoris-Myocardial Infarction Investigations in Japan. Transient left ventricular apical ballooning without coronary artery stenosis: a novel heart syndrome mimicking acute myocardial infarction. Angina 
Pectoris-Myocardial Infarction Investigations in Japan. J Am Coll Cardiol. 2001;38:11-8.

10. Kurisu $S$, Inoue I, Kawagoe $T$, Ishihara M, Shimatani $Y$, Hata T, Nakama Y, Kijima Y, Kagawa E. Persistent left ventricular dysfunction in takotsubo cardiomyopathy after pacemaker implantation. Circ J. 2006;70:641-4.

11. Kounis NG, Koniari I, Soufras G; Kounis Syndrome After Intake of Levofloxacin: Increasing Incidence of Hypersensitivity to Fluoroquinolones J Investig Allergol Clin Immunol. 2017; 27(1):76-7.
- Manuscript received March 2, 2017; accepted for publication March 17, 2017.

\section{- Ignacio Garcia-Nunez}

Allergy Department
Hospital Quironsalud Malaga
Avda Imperio Argentina n ${ }^{\circ} 1$
29004 Malaga
Email: h62ganui@hotmail.com 